\title{
Pharmacy students' views on the objective structured clinical examination (OSCE): findings from two Malaysian universities
}

\author{
Mohamed Hassan Elnaem¹,2, Muhammad Zuljalil Ilham Bin Wahab11, Aqilah Binti Mohd Ali, Umi Syuhada Binti \\ Abd Rahim ${ }^{1}$, Nuraqilah Binti Zulkifli¹, Nur Syaza Binti Mohd Akbar Basha1, Maidatul Suffiah Hayati Binti Mohamad \\ Yusof1, Nur Farhana Binti Mohd Majdy1, Zainol Akbar Zainal3 \\ 1Department of Pharmacy Practice, Faculty of Pharmacy International Islamic University Malaysia, Kuantan, Pahang, Malaysia \\ ${ }^{2}$ Quality use of medicines research group, Faculty of Pharmacy, International Islamic University Malaysia, Kuantan, Pahang, Malaysia \\ ${ }^{3}$ Faculty of Pharmacy, University of Cyberjaya University, Persiaran Bestari, Cyber 11, Cyberjaya, Selangor, Malaysia
}

\section{Keywords}

Clinical skills

Malaysia

OSCE

Pharmacy student

Views

\begin{abstract}
Objectives: To investigate and compare the views of undergraduate pharmacy students in two Malaysian pharmacy schools (one private and one public) regarding the organisation, quality, and objectivity of Objective Structured Clinical Examination (OSCE). Methods: A cross-sectional study was undertaken among penultimate and final year students in two Malaysian pharmacy schools between October to December 2019 (International Islamic University Malaysia [IIUM] and University of Cyberjaya [UoC]). A questionnaire was developed, tested, validated and then distributed to study participants through online Google forms. Results: A total of 221 undergraduate pharmacy students participated in the study. Students from the public university disagreed with the allocated time for the OSCE stations (IIUM $63.9 \%$ and $48.7 \%$ vs UoC $11.6 \%$ and $14.3 \%$ ). Relatively few students agreed that OSCE is a less stressful type of assessment compared to other traditional methods (IIUM $7.2 \%$ and $10.3 \%$ vs UoC $39.5 \%$ and $23.8 \%$ ). Both groups of students disagreed that OSCE marks were likely to be affected by the student's gender (IIUM 73.2\% and $66.7 \%$ vs UoC $67.4 \%$ and $78.6 \%$ ). Private university students agreed more than their counterparts in public university that the OSCE scores were valid indicators of the students' skills (UoC $79 \%$ and $64.3 \%$ vs IIUM $39.2 \%$ and $30.8 \%$ ). Conclusion: The majority of participants had positive views on the organisation, quality, and objectivity of OSCE, with several differences between students in public and private universities. There are few areas to be further considered to ensure more positive OSCE experience for students such as revision on the time allocation for every station and on the provision of timely constructive feedback.
\end{abstract}

\section{Introduction}

The objective structured clinical examination (OSCE) was introduced as early as 1975 as an assessment method for students in clinical disciplines (Harden et al., 1975). It comprises various stations where candidates are required to perform a wide range of real life clinical tasks and respond to simulated clinical queries. These tasks should be carried out within time limits, including limits on time for interaction with simulated patients or healthcare providers (Gupta et al., 2011; Shirwaikar, 2015). For the interactive stations, a trained examiner is placed to observe and assess the candidates based on a standardised marking scheme meanwhile, written responses will be evaluated instead of observations at the non-interactive stations (Shirwaikar, 2015). With the shift in paradigm for pharmacy practice to become more patient-focused, using OSCE became an essential 
assessment part at schools of pharmacy worldwide and adapted by several pharmacist professional associations for certifying and licensing purposes (Austin et al., 2003; Shirwaikar, 2015).

In Malaysia, 21 pharmacy schools are entitled to offer undergraduate pharmacy programmes; of these six programmes are offered in public universities, and the rest are in private universities, either national or affiliated with international universities ('List of Authorized Local Universities Offering Pharmacy Course | Pharmaceutical Services Programme,' n.d.). Generally, the Malaysian undergraduate pharmacy programmes are designed as four-year programmes succeeded later by a one-year provisional training in hospital, community, industry, or academic institutions (Hassali, Mak \& See, 2014). Moreover, it is important to notice the initiatives taken by few Malaysian pharmacy schools to offer specialised clinical pharmacy courses to meet the growing interest of undergraduate students in the clinical subjects (Elnaem, Jamshed \& Elkalmi, 2017; Elnaem et al., 2018).

As an integral assessment component of the learning process, most pharmacy schools in Malaysia are conducting OSCE to assess a wide range of their students' skills. It is well-established that a well-structured OSCE is the best method to assess the students' skills of communication, professional judgment, and problemsolving skills in clinical health professions academic programs (Salinitri et al., 2012; Shirwaikar, 2015). Little has been known about the Malaysian pharmacy students' views and perspectives regarding the OSCE conducted to assess their skills and competencies (Awaisu, Mohamed \& Al-Efan, 2007). To the best of the authors' knowledge, no previous study has reported perspectives of students of both private and public universities concerning the extent of OSCE organisation and objectivity. Therefore, this work aimed to investigate and compare the views of undergraduate pharmacy students in two Malaysian pharmacy schools, one private and one public, regarding the organisation, quality, and objectivity of OSCE.

\section{Methods}

\section{Study design}

A descriptive cross-sectional study was conducted to explore and compare the views of the penultimate and final-year undergraduate pharmacy students in two of the Malaysian public and private universities concerning the organisation, quality, and objectivity of the OSCE assessment.
Development, validity, and reliability of the study instrument

A self-designed 23-item structured questionnaire in English was developed as no similar tool to achieve the research objectives was found in the literature. The content validity of the developed tool was examined by an expert panel of three academic staff from the department of pharmacy practice at International Islamic University Malaysia (IIUM), whose experience in designing OSCE assessment. Accordingly, the content validity index for each item was calculated, and the inputs from the experts' panel were considered making all necessary amendments. Upon validation, the finalised draft was transformed into an online Google form to be easily distributed for the pilot testing of the instrument. The selection of students for pilot testing was done randomly by the research team, and they have been excluded from participating in the main study. The outputs of the pilot study were utilised to assess the internal consistency and reliability of the instrument before using it in the main study. The Cronbach's alpha value was calculated at 0.87 , which was regarded as an acceptable value (Tavakol \& Dennick, 2011).

\section{Description of the study instrument}

The study instrument was divided into three sections. Section one is composed of three items of general information and participants' demographics. Section two contained six questions used to assess the views of the students regarding the organisation of OSCE. Section three consisted of a total of 14 designed to explore the opinion of students about the OSCE Quality and Objectivity. Items in sections two and three were designed to be answered on a five-item Likert scale where one denoted 'strongly disagree,' and 5 indicated 'strongly agree'. So excluding the first introductory section of the questionnaire, the survey comprised a total of twenty questions. The estimated average time to complete the questionnaire was 15 to 20 minutes referring to the pilot study responses.

\section{Study participants and sample size}

The target participants of the study were penultimate and final-year students in the pharmacy schools of a public university (International Islamic University Malaysia 'IIUM') and a private university (University of Cyberjaya ' $\mathrm{OCC}^{\prime}$ ). The selection of students in the last two years of the study program was based on confirmation of their previous exposure to the OSCE. The subjects who have been 
involved in the pilot study were excluded from real study participation. The participation of subjects was voluntarybased, and no payment was given. The student's consent form was implied by the submission of the completed questionnaires. The expected target population for the main study was 387 from both universities, 250 students from IIUM, and 137 students from UoC. At least 194 participants were needed to fulfil the requirement of the sample size calculation by RAOSOFT calculator with a $5 \%$ margin error and a 95\% confidence level. A link to the online questionnaire was communicated to all potential study participants that followed by at least three reminders were sent to increase the response rate.

\section{Ethical requirements}

The study protocol obtained ethical approval from the IIUM Research Ethics Committee (IREC). Private and confidential information regarding students' involvement was kept secure and respected as the identity of the student was anonymous. The study conducted should, by any means, cause no harm to people and the environment.

\section{Statistical analysis}

The data were analysed using SPSS software version 23. Descriptive data were expressed in percentages. KruskalWallis test was utilised to compare the differences in the mean questionnaire scores between the students' groups and between study levels in both universities. The level of significance was set at $p<0.05$.

\section{Results}

\section{Demographic information}

A total of 387 students were identified as target respondents, and 221 questionnaires were collected online (response rate $57.1 \%$ ) which achieved the target respondents' limit (more than 194 respondents). The response rates in each of IIUM and UoC were $n=134$, $53.7 \%$, and $n=87,63.4 \%$, respectively. About $61.5 \%$ of the total responses were from IIUM (47\% female \& $14.5 \%$ male) whereas $38.5 \%$ ( $29 \%$ female \& $9.5 \%$ male) were from UoC. Finally, $63.4 \%$ of the total responses were from penultimate students; meanwhile, $36.6 \%$ were responses from final year students.

\section{Students' Views on the OSCE organisation}

In this domain, six items explored the students' views on the overall organisation of the OSCE. Students responded with an agreement to the survey items except for the item of time allocation where students of the public university have expressed a relatively higher level of disagreement (IIUM $63.9 \%$ \& $48.7 \%$ vs UoC $11.6 \%$ \& 14.3\%). Also, there was a higher level of agreement among final year students and those belonging to the private university. For the ease of responses' presentation, responses were grouped into three categories; agree, neutral, and disagree. All items showed significant differences between students' groups and years of study except for item 5 , which was related to counselling techniques indicating the relative agreement between study groups that counselling techniques are usually presented in their OSCE tasks. Table I presents the percentages of the students' responses to the items of the OSCE organisation.

Table I: Views of students towards OSCE organisation (expressed in percentages)

\begin{tabular}{|c|c|c|c|c|c|c|c|c|c|c|c|c|c|}
\hline \multirow{3}{*}{$\begin{array}{l}\text { Students' groups per different years in each university } \\
\text { Students' responses (expressed in percentages) }\end{array}$} & \multicolumn{6}{|c|}{ IIUM (N=134) } & \multicolumn{6}{|c|}{ UoC ( $N=87)$} & \multirow{3}{*}{$\begin{array}{c}p- \\
\text { value* }\end{array}$} \\
\hline & \multicolumn{3}{|c|}{ Year 3 (\%) } & \multicolumn{3}{|c|}{ Year 4 (\%) } & \multicolumn{3}{|c|}{ Year 3 (\%) } & \multicolumn{3}{|c|}{ Year 4 (\%) } & \\
\hline & A & $\mathbf{N}$ & D & A & $\mathbf{N}$ & D & A & $\mathbf{N}$ & D & A & $\mathbf{N}$ & D & \\
\hline 1) The instructions at the OSCE stations were well understood & 66 & 25.8 & 8.2 & 77 & 12.8 & 10.2 & 88.4 & 11.6 & 0.00 & 83.4 & 9.5 & 7.1 & 0.02 \\
\hline 2) Time provided for every task at a station was adequate & 13.4 & 22.7 & 63.9 & 12.8 & 38.5 & 48.7 & 72.1 & 16.3 & 11.6 & 66.7 & 19 & 14.3 & $<0.001$ \\
\hline 3) Briefing regarding the flow of OSCE before the exam was adequate & 53.6 & 33 & 13.4 & 76.9 & 18 & 5.1 & 74.4 & 18.6 & 7 & 88.1 & 4.8 & 7.1 & $<0.001$ \\
\hline 4) The materials provided during OSCE were sufficient & 52.6 & 28.9 & 18.5 & 82 & 7.7 & 10.3 & 93 & 7 & 0.00 & 95.2 & 2.4 & 2.4 & $<0.001$ \\
\hline 5) Questions in OSCE were mainly focused on counselling techniques & 63.9 & 21.7 & 14.4 & 43.6 & 28.2 & 28.2 & 67.4 & 18.6 & 14 & 64.3 & 28.6 & 7.1 & 0.057 \\
\hline 6) The overall layout during OSCE was convenient & 60.8 & 25.8 & 13.4 & 79.5 & 15.4 & 5.1 & 93 & 7 & 0.00 & 98.1 & 11.9 & 0.00 & $<0.001$ \\
\hline
\end{tabular}

Agree $=A$, Neutral $=N$, Disagree $=D$

*using Kruskal-Wallis Test 


\section{Students' Views on the OSCE objectivity and quality}

This domain had mixed items of the students' opinions of the quality and objectivity of the OSCE. All items showed significant differences between students' groups and years of study except for items 11,13, and 18. Relatively few students agreed that OSCE is a less stressful type of assessment compared to other traditional methods (IIUM $7.2 \%$ \& $10.3 \%$ vs UoC $39.5 \%$ \& $23.8 \%)$. Students in the public university were less in agreement that OSCE might help to reduce the failure rate of the subject (IIUM 22.7\% \& $46.2 \%$ vs UoC $60.5 \%$ \& $42.9 \%)$. Regarding the OSCE scores as valid indicators of the student's skills, students from the private university had more agreement compared to their counterparts in a public university (UoC $79 \%$ \& $64.3 \%$ vs IIUM $39.2 \% \quad 30.8 \%$ ). Besides, both students' groups disagreed that OSCE marks were likely to be affected by the student's gender (IIUM 73.2\% \& 66.7\% vs UoC $67.4 \%$ \& $78.6 \%)$. However, the impact of student's characters on the OSCE assessment was highlighted with relatively fewer concerns among final year students in a public university (IIUM 68\% \& $35.9 \%$ vs UoC $62.8 \%$ \& $66.7 \%)$. Table II demonstrates the responses of the students regarding the items of the quality and objectivity of the OSCE.

\section{Discussion}

Most participants had overall good opinions regarding the organisation, quality, and objectivity of OSCE. Similarly, previous research involved a smaller number of participants at one Malaysian university reported that many participants perceived their OSCE as a good, comprehensive, and fair experience (Awaisu et al., 2007). More important, there was a significant difference between students' groups concerning their opinions regarding the adequacy of allocated time for OSCE stations. The students from a public university whose OSCE was designed as seven-minute stations were more concerned about the allocated time compared to those from a private university whose OSCE was designed as 10minute stations. The students' concerns about having sufficient time to perform the required tasks at the OSCE stations were highlighted frequently in the literature (Salih et al., 2010; Kristina, Gustriawanto et al., 2018). It seems that the allocation of slightly more time could contribute to making the OSCE experience less stressful from students' perspectives.

Concerning the feedback given after the OSCE and its efficiency in helping students learn from their mistakes,

Table II: Views of students towards OSCE quality and objectivity

\begin{tabular}{|c|c|c|c|c|c|c|c|c|c|c|c|c|c|}
\hline \multirow{3}{*}{$\begin{array}{l}\text { Students' groups per different years in each university } \\
\text { Students' responses (expressed in percentages) }\end{array}$} & \multicolumn{6}{|c|}{ IIUM (N=134) } & \multicolumn{6}{|c|}{ UoC ( $N=87)$} & \multirow{3}{*}{$P$-Value } \\
\hline & \multicolumn{3}{|c|}{ Year 3} & \multicolumn{3}{|c|}{ Year 4} & \multicolumn{3}{|c|}{ Year 3} & \multicolumn{3}{|c|}{ Year 4} & \\
\hline & A & $\mathbf{N}$ & D & A & $\mathbf{N}$ & D & A & $\mathbf{N}$ & D & A & $\mathbf{N}$ & D & \\
\hline 7) OSCE was a less stressful exam compared to other exams & 7.2 & 20.6 & 72.2 & 10.3 & 28.2 & 61.5 & 39.5 & 25.6 & 34.9 & 23.8 & 38.1 & 38.1 & $<0.001$ \\
\hline 8) OSCE helps in reducing the failure in a particular subject & 22.7 & 43.3 & 34 & 46.2 & 23 & 30.8 & 60.5 & 30.2 & 9.3 & 42.9 & 50 & 7.1 & $<0.001$ \\
\hline $\begin{array}{l}\text { 9) Students were able to identify their mistakes from the feedback } \\
\text { given by the assessor regarding their performance on OSCE }\end{array}$ & 69 & 15.5 & 15.5 & 35.9 & 18 & 46.1 & 83.7 & 14 & 2.3 & 92.9 & 4.7 & 2.4 & $<0.001$ \\
\hline 10) The marks were affected by the characters of the students & 68 & 24.8 & 7.2 & 35.9 & 41 & 23.1 & 62.8 & 27.9 & 9.3 & 66.7 & 26.2 & 7.1 & 0.002 \\
\hline 11) The marks were affected by the gender of the students & 8.3 & 18.5 & 73.2 & 5.1 & 28.2 & 66.7 & 18.6 & 14 & 67.4 & 9.5 & 11.9 & 78.6 & 0.582 \\
\hline $\begin{array}{l}\text { 12) The level of difficulty in OSCE is aligned with the students' level } \\
\text { of knowledge }\end{array}$ & 60.8 & 23.7 & 15.5 & 56.4 & 41 & 2.6 & 86 & 11.6 & 2.4 & 76.2 & 16.7 & 7.1 & 0.007 \\
\hline $\begin{array}{l}\text { 13) Knowledge and skills gained from OSCE are relevant to future } \\
\text { pharmacists }\end{array}$ & 88.7 & 8.2 & 3.1 & 89.7 & 10.3 & 0 & 97.7 & 2.3 & 0 & 97.6 & 2.4 & 0 & 0.130 \\
\hline 14) OSCE covered wide area of clinical skills in pharmacy practice & 74.2 & 21.7 & 4.1 & 79.5 & 20.5 & 0 & 93 & 4.7 & 2.3 & 97.6 & 0 & 2.4 & 0.002 \\
\hline $\begin{array}{l}\text { 15) OSCE scores are true indicators of students' essential clinical } \\
\text { skills }\end{array}$ & 39.2 & 32 & 28.8 & 30.8 & 38.4 & 30.8 & 79 & 16.3 & 4.7 & 64.3 & 23.8 & 11.9 & $<0.001$ \\
\hline $\begin{array}{l}\text { 16) Students were able to apply the knowledge that had been } \\
\text { taught in the class }\end{array}$ & 74 & 19 & 7 & 76.9 & 18 & 5.1 & 93 & 7 & 0 & 95.2 & 4.8 & 0 & 0.003 \\
\hline $\begin{array}{l}\text { 17) Students were able to practice their skills rather than just } \\
\text { memorising facts for OSCE }\end{array}$ & 83.5 & 12.4 & 4.1 & 82.1 & 12.8 & 5.1 & 88.4 & 11.6 & 0 & 100 & 0 & 0 & 0.037 \\
\hline $\begin{array}{l}\text { 18) OSCE trained the students to be more confident when dealing } \\
\text { with patients and health professionals in the future }\end{array}$ & 89.7 & 8.2 & 2.1 & 84.6 & 12.8 & 2.6 & 95.3 & 4.7 & 0 & 100 & 0 & 0 & 0.051 \\
\hline $\begin{array}{l}\text { 19) OSCE enhanced the interest of students towards clinical } \\
\text { pharmacy }\end{array}$ & 68 & 26.8 & 5.2 & 64.1 & 28.2 & 7.7 & 90.7 & 6.9 & 2.4 & 81 & 19 & 0 & 0.010 \\
\hline $\begin{array}{l}\text { 20) The students became more motivated to increase their level } \\
\text { of competency after OSCE }\end{array}$ & 62.9 & 29.9 & 7.2 & 61.5 & 28.2 & 10.3 & 93 & 7 & 0 & 88.1 & 11.9 & 0 & $<0.001$ \\
\hline
\end{tabular}


there was a noticeable difference between students' groups. Final year students and particularly those from a public university were more concerned about the quality and timely receiving of feedback regarding their OSCE performance. This could be attributed to the fact that in the final year, there is more than one course that uses OSCE as an assessment that requires conducting of many OSCEs in a relatively short period. That could make it more challenging for lecturers to provide extensive and detailed feedback for students on how to prepare themselves for the next examination session.

Moreover, the majority of students in both universities believed that OSCE scores are true indicators of students' essential clinical skills. There were some differences in the extent of students' agreement to this statement in favour of penultimate students and final year students from a private university. In contrast, previous research conducted to explore students' opinions regarding the objectivity and validity of OSCE has highlighted that students were having different views on the acceptance of the OSCE as the main evaluation assessment of their clinical skills (Almuqdadi et al., 2017; Alkhathlan et al., 2018). Overall, the participants in our study had a good acceptance level of the OSCE to evaluate their clinical skills. Furthermore, concerning the objectivity of the assessment, most of the study participants did not see any significant contribution of other non-academic factors such as student's gender on the quality of examination. Moreover, in particular, final year students in the public university acknowledged no significant impact of students' characters on the obtained OSCE scores. This finding is in line with previous research conducted on medical students that reported the lack of perception that students' characteristics played a role in their obtained scores (Azim Majumder et al., 2019). In contrast, in a previous UK study that aimed to explore pharmacy students' feedback on the assessment methods, a significant number of participants have highlighted the potential impact of students' characteristics on their final OSCE scores (Hanna, Davidson \& Hall, 2017).

Concerning the perceived stress associated with the OSCE, previous research on OSCE experience among healthcare students has highlighted the students' anxiety associated with their OSCE (Fidment, 2012). Similarly, our study participants, particularly those from a public university, had the same opinions that OSCE was a stressful learning experience. Moreover, previous research showed that the majority of pharmacy students tend to visualise the OSCE as a more stressful assessment compared to other assessment methods (Hanna et al., 2017). In addition, another study among medical students underscored that they had perceived the OSCE as being more difficult compared to the traditional assessment, such as essay questions (Azim Majumder et al., 2019).

Overall, students in our sample have reported good views about the importance of OSCE and its potential contribution to help them in developing their skills towards their future healthcare professional career. They have also reported that the layout of the examination was comfortable. This in line with the previous findings that highlighted that health care students tend to view the OSCE as a worthwhile experience that, with some fine adjustments, could be less stressful and more efficient (Fidment, 2012). Among the adjustments that could be considered in our setting is the revision of the time allocation for every station, the focus on providing timely constructive feedback, and the further efforts should be exerted to motivate the students to maximise their benefits from this learning experience.

There is no work without limitations. Although our study involved responses from two schools of pharmacy, it still lacks the generalisability to represent the OSCE views of the whole Malaysian pharmacy students. In addition, it is assumed that a more prolonged period for data collection would contribute to a higher response rate.

\section{Conclusion}

Overall, most participants had good views regarding the organisation, quality, and objectivity of OSCE, with several differences between students in public and private universities. There are few improvement areas to be further considered, such as revision of the time allocation for every station and provision of timely constructive feedback, to ensure that students had a more positive and less stressful OSCE experience. The findings supported no significant contribution of other non-academic factors such as student's gender on the OSCE assessment scores.

\section{References}

Alkhathlan, T. K., Alsultan, A. H., Alzaid, F. N., Alrajhi, M. N., Mohamed, T. A., \& Masuadi, E. (2018). Medical Students ' Perception of The Effectiveness of Objective Structured Clinical Examination ( OSCE ) in Phase 2 (The Pre-Clinical Phase) at King Saud Bin Abdulaziz University for Health Sciences. The Egyptian Journal of Hospital Medicine, 71(7), 3554-3558. https://doi.org/ $\underline{10.12816 / 0047675}$

Almuqdadi, A., Yousef, A.M., Majdalawi, K., Masoud, Z., Kalabani, R., \& Al-Hadeed, H. (2017). Validation and evaluation of an OSCE in undergraduate doctor of pharmacy program. Indian Journal of Pharmaceutical Education and Research, 51(3), 380-387. https:// doi.org/10.5530/ijper.51.3.64 
Austin, Z., O’Byrne, C., Pugsley, J., \& Munoz, L.Q. (2003). Development and validation processes for an objective structured clinical examination (OSCE) for entry-to-practice certification in pharmacy: The Canadian experience. American Journal of Pharmaceutical Education, 67(3), Article 76. https:// doi.org/10.5688/aj670376

Awaisu, A., Mohamed, M.H.N., \& Al-Efan, Q.A.M. (2007). Perception of pharmacy students in Malaysia on the use of objective structured clinical examinations to evaluate competence. American Journal of Pharmaceutical Education, 71(6), Article 118. https://doi.org/10.5688/aj7106118

Azim Majumder, A., Kumar, A., Krishnamurthy, K., Ojeh, N., Adams, O. P., \& Sa, B. (2019). An evaluative study of objective structured clinical examination (OSCE): students and examiners perspectives. Advances in Medical Education and Practice, 10(June), 387-397. https://doi.org/10.2147/amep.s197275

Elnaem, M.H., Bin Che Ibrahim, M.Z., Abdul Rahman, N.A.H., Binti Mahyidin, N.H., Binti Sulaiman, N.M., \& Binti Zulkiflee, F.A. (2018). Knowledge and perceptions toward cardiology pharmacy education and training: Malaysian pharmacy students' perspectives. Currents in Pharmacy Teaching and Learning, 10(4), 453-462. https://doi.org/10.1016/i.cptl.2017.12.019

Elnaem, M.H., Jamshed, S.Q., \& Elkalmi, R.M. (2017). The future of pharmaceutical care in Malaysia: Pharmacy students' perspectives. Pharmacy Education, 17(1), 215-222

Fidment, S. (2012). The Objective Structured Clinical Exam (OSCE): A Qualitative Study Exploring the Healthcare Student's Experience. Student Engagement and Experience Journal, 1(1), 1-18. https://doi.org/10.7190/seej.v1i1.37

Gupta, M., Seth, A., Rose, J., \& Parijatham, B.O. (2011). Objective structured clinical examination (OSCE) in pathology. Journal of Clinical and Diagnostic Research, 5(5), 1134

Hanna, L.A., Davidson, S., \& Hall, M. (2017). A questionnaire study investigating undergraduate pharmacy students' opinions on assessment methods and an integrated five-year pharmacy degree. Pharmacy Education, 17(1), 115-124

Harden, R.M.G., Downie, W. W., Stevenson, M., \& Wilson, G. M. (1975). Assessment of Clinical Competence using Objective Structured Examination. British Medical Journal, 1(5955), 447451. https://doi.org/10.1136/bmj.1.5955.447

Hassali, M.A., Mak, V.S.L., \& See, O.G. (2014). Pharmacy practice in Malaysia. Journal of Pharmacy Practice and Research, 44(3), 125-128. https://doi.org/10.1002/jppr.1024

Kristina, S. A., Gustriawanto, N., Rokhman, M. R., Aditama, H., \& Sari, I. P. (2018). Students' first experience with objective structured clinical examination in a pharmacy school in Indonesia. Journal of Applied Pharmaceutical Science, 8(9), 102106. https://doi.org/10.7324/JAPS.2018.8915

List of Authorized Local Universities Offering Pharmacy Course | Pharmaceutical Services Programme. (n.d.). Retrieved April 14, 2020, from https://www.pharmacy.gov.my/v2/en/content/listauthorized-local-universities-offering-pharmacy-course.html

Salih, M. R. M., Baidi Bahari, M., Syed Sulaimam, S. A., Sarriff, A., Yaseen, S. N., \& Oktavia Sari, Y. (2010). Pharmacy student perceptions and feedback on the modified Objective Structured Clinical Examination. Pharmacy Education, 10(2), 165-172.

Salinitri, F. D., O'Connell, M. B., Garwood, C. L., Lehr, V. T., \& Abdallah, K. (2012). An objective structured clinical examination to assess problem-based learning. American Journal of Pharmaceutical Education, 76(3), Article 44. https://doi.org/ 10.5688/ajpe76344
Shirwaikar, A. (2015). Objective structured clinical examination (OSCE) in pharmacy education- A trend. Pharmacy Practice, 13(4), 1-5. https://doi.org/10.18549/PharmPract.2015.04.627

Tavakol, M., \& Dennick, R. (2011). Making sense of Cronbach's alpha. International Journal of Medical Education, 2, 53-55. https://doi.org/10.5116/ijme.4dfb.8dfd 